\title{
Past Stimulant Abuse is Associated with Reduced Basal Ganglia and Hippocampal Integrity in Older HIV+ Adults: A Diffusion Tensor Imaging Study
}

\author{
Thames $\mathrm{AD}^{1,3^{*}}$, Foley $\mathrm{JM}^{2}$, Panos $\mathrm{SE}^{1,3}$, Singer $\mathrm{EJ}^{1}$, Patel $\mathbf{S M}^{1,3}$, El-Saden $\mathbf{S}^{1,3}$ and Hinkin $\mathbf{C H}^{1,3}$ \\ ${ }^{1}$ UCLA School of Medicine 760 Westwood Plaza Los Angeles, CA 90095, USA \\ ${ }^{2}$ Boston VA Healthcare System/Harvard Medical School 150 S. Huntington Avenue Boston, MA 02130, USA \\ ${ }^{3}$ VA Greater Los Angeles Healthcare System 11310 Wilshire Blvd Los Angeles, CA 90073, USA
}

\begin{abstract}
Human Immunodeficiency Virus (HIV) and current stimulant abuse have both been shown to damage basal ganglia and hippocampus. While the effects of current stimulant abuse on neurological functioning is welldocumented, whether residual damage can be detected in patients with a distant history of past stimulant abuse/ dependence remains to be understood. Given that past stimulant abuse is common among HIV-infected individuals: this is a question of considerable clinical significance. The present study employed Diffusion Tensor Imaging (DTI) and structural MRI to examine brain integrity (as measured by FA and MD) and volume in the basal ganglia (BG) and hippocampus among older HIV-infected adults with histories of stimulant abuse. Lower fractional anisotropy and greater diffusivity (representative of microstructural breakdown) in basal ganglia and hippocampal structures were documented among former stimulant abusers compared to stimulant-naïve individuals. Length of abstinence was also associated with BG integrity, such that those with shorter abstinence periods demonstrated greater MD of the BG. Our findings suggest that past stimulant abuse is associated with neurological dysfunction, though this improves with increasing abstinence.
\end{abstract}

Keywords: Past stimulant abuse; Diffusion tensor imaging (DTI); Human immunodeficiency virus (HIV); Aging; Basal ganglia; Hippocampus

\section{Introduction}

Older adults are one of the fastest growing subgroups among the HIV infected population. By the year 2015 they are predicted to comprise $50 \%$ of all HIV infected individuals in the US population (CDC, 2007) and therefore understanding the factors that contribute to morbidity in this increasingly prevalent subgroup remains paramount. Older adults with HIV are particularly vulnerable to CNS dysfunction due to overlapping neuropathological processes common to both normal aging and HIV. A number of studies have demonstrated that older HIV-infected adults have higher prevalence and severity of cognitive abnormality when compared to both younger HIV+ and HIV-seronegative healthy elderly controls [1-7]. Yet, very few studies have looked within the older HIV cohort to understand factors that may place some older adults at risk for cognitive and functional decline. Substance abuse is one such factor with particular relevance to this population.

Substance abuse is a common comorbidity in HIV and can result in behavioral consequences such as poor medication adherence, impulsivity, and risky decision-making [8,9]. Multiple studies have shown that HIV-infected drug abusers evidence more severe neurocognitive dysfunction than non-drug-abusing HIV-infected individuals [10-13] And among older adults, the need for substance abuse treatment is estimated to increase from 1.7 million in 2000 and 2001 to 4.4 million in 2020 [14]. Therefore, a critically important question that must be answered is, "Does past stimulant abuse lead to downstream neurological dysfunction in older adulthood among HIV positive individuals?" Based upon results from prior investigations, there is reason to suspect that older adults with substance abuse histories are at disproportionate risk for both neurological and cognitive decline, and in particular individuals with histories of stimulant abuse more specifically (including cocaine and/or methamphetamine) demonstrate localized basal ganglia degeneration among a host of additional neuropathological responses.

\section{Cocaine, HIV and neurological dysfunction}

Cocaine use up-regulates cytokine release impairing macrophage and $\mathrm{CD} 4+\mathrm{T}$ cell function which in turn accelerates HIV progression Friedman et al. $(2003)[15,16]$. Cocaine is also known to modulate the expression of interleukin (IL)-10 [17,18] a cytokine involved in HIV replication. Dhillon and colleagues [19] found that cocaine potentiates the expression of HIV-1 in human macrophages and in latently infected promonocytic $\mathrm{U} 1$ cells. Increases were associated with activation of NF$\kappa \mathrm{B}$ and egr-1, and proviral LTR activity, increases in IL-10 production, and activation of macrophages.

Studies examining the neurotoxic effects of cocaine use among individuals with HIV have found that cocaine potentiates viral replication [20] and results in decreases in dopamine receptor (D2) availability [21]. Both cocaine and HIV can downregulate tight junction proteins, thereby increasing endothelial permeability $[22,23]$. In a study comparing cocaine dependent individuals to healthy controls, cocaine dependence was associated with decreased grey matter volume in

*Corresponding author: April D. Thames, Ph.D, UCLA School of Medicine Department of Psychiatry and Biobehavioral Sciences,760 Westwood Plaza, Los Angeles, CA 90095, USA, Tel: (310) 268-3078; Fax: (310) 206-8525; E-mail: athames@mednet.ucla.edu

Received September 29, 2011; Accepted December 02, 2011; Published December 05, 2011

Citation: Thames AD, Foley JM, Panos SE, Singer EJ, Patel SM, et al. (2011) Past Stimulant Abuse is Associated with Reduced Basal Ganglia and Hippocampal Integrity in Older HIV+ Adults: A Diffusion Tensor Imaging Study. J AIDS Clinic Res 2:129. doi:10.4172/2155-6113.1000129

Copyright: @ 2011 Thames, et al. This is an open-access article distributed unde the terms of the Creative Commons Attribution License, which permits unrestricted use, distribution, and reproduction in any medium, provided the original author and source are credited. 
Citation: Thames AD, Foley JM, Panos SE, Singer EJ, Patel SM, El-Saden S and Hinkin CH et al. (2011) Past Stimulant Abuse is Associated with Reduced Basal Ganglia and Hippocampal Integrity in Older HIV+ Adults: A Diffusion Tensor Imaging Study. J AIDS Clinic Res 2:129. doi:10.4172/21556113.1000129

Page 2 of 6

orbitofrontal, cingulate, insular, temporoparietal and cerebellar cortex, and with a more localized increase in grey matter volume in the basal ganglia. Greater duration of cocaine dependence was correlated with greater grey matter volume reduction in orbitofrontal, cingulate and insular cortex and increased volume of caudate nucleus [24].

During a task that manipulates immediate versus delayed rewards, HIV + recovered cocaine users demonstrated a more complex pattern of brain activation during the delayed rewards when compared to current users and drug-naïve controls. For easy choices, recovered users performed similarly to drug naïve participants, with greater increases in activation in the anterior cingulate cortex (ACC), orbitofrontal cortex (and the overlapping ventromedial prefrontal cortex (areas involved in decision making) compared to active cocaine users. In contrast, for hard choices, recovered users evidenced deficits similar to those observed in active cocaine users, suggesting that sustained remission from cocaine use may reverse some, but not all, of the impairments associated with active cocaine dependence [25].

\section{Methamphetamine, HIV and basal ganglia dysfunction}

Since the early 1990s, there has been a rise in the number of individuals abusing methamphetamine (METH) in the U.S. According to the U.S. 2006 National Survey on Drug Use and Health, approximately 10 million people (around $4.5 \%$ of the U.S. population) have experimented with METH at some point in their lives, while 1.3 million persons reported using METH in the past year (Substance Abuse and Mental Health Services Administration [SAMHSA], 2006) [26].

METH has high lipid solubility, allowing more rapid transport of the drug across the blood-brain barrier [27]. METH administration stimulates the release of dopamine and alters functions of the dopamine transporter (DAT), thus resulting in neurotoxicity [28].. High dose and chronic administration of METH can result in depletion of dopamine and destruction of dopamine nerve terminals $[29,30]$. There is suggestion that dopamine levels are more severely reduced in the caudate than in the putamen [31]. Jernigan and colleagues [32] examined the synergistic effects of HIV and METH use on brain volume and found overlapping, and in some instances opposing, effects of METH dependence and HIV on brain volumes. For some structures, the independent effects of HIV or METH were more dominant and resulted in differential regional patterns. Interestingly, volume increases in the basal ganglia were reported among METH abusers and possibly represent compensatory responses to neuroinflammation and astrogliosis.

Similarly, Chang and colleagues [33] observed larger BG volumes in chronic METH users, possibly representing a functional compensatory response. In a follow-up study using proton MR, reduced markers of neuronal integrity and increased markers of gliosis were found in the cerebral cortex and basal ganglia, suggesting that glial proliferation may follow neural damage [34]. Using diffusion tensor imaging (DTI), lower fractional anisotropy (i.e., less directional diffusivity of water, possibly indicating decreased parallel ordering of axons) values were found bilaterally in the frontal white matter of $32 \mathrm{METH}$ abusers compared with 30 healthy comparison subjects [35].

Hippocampal abnormalities have also been associated with METH use. Chronic METH use resulted in a selective pattern of cerebral deterioration near hippocampal structures which contributed to impaired memory performance [36]. Chronic METH has also been associated with impairing neural progenitor cells (NPCs), which are produced in the adult hippocampus and play a role in hippocampal- dependent cognitive functions [37]. Among abstinent METH users, Kim and colleagues [38] examined differences in gray matter density in abstinent METH-dependent participants. METH participants displayed a gray-matter deficit in the right middle frontal gyrus when compared to controls, and this deficit was more prominent in those who were newly abstinent (less than six months) compared to those who achieved sustained abstinence.

\section{HIV-associated basal ganglia dysfunction}

HIV enters the CNS early in the course of infection generating a cascade of immunological responses that preferentially target striatal functions [39]. Histopathological investigations of postmortem brain tissue have demonstrated the highest levels of HIV in the basal ganglia [40,41]. Examinations of biochemical metabolites have observed lower levels of $\mathrm{N}$-acetylaspartate (a marker of neuronal integrity) and higher levels of choline and myoinsonital (markers of inflammation and cell turn over) in the basal ganglia of HIV infected patients. Studies using structural MRI have demonstrated volume reductions in subcortical structures and white matter microstructural pathology $[42,43]$. More recently, DTI is being used to examine basal ganglia dysfunction in HIV. Although typically used as a method for studying white matter microstructure, DTI is becoming increasingly used as a tool to measure gray matter integrity as well Wang et al. (2009) [44,45].

DTI provides a quantitative noninvasive method for delineating structural abnormality by measuring the extent and directionality of water diffusion in n-directional space. The directionality of diffusion can be quantified by fractional anisotropy (FA), while mean diffusivity (MD) indicates the degree of diffusion Sullivan et al. [46]. Alterations in subcortical integrity may reflect changes in relative intracellular/ extracellular volumes or net loss of structural barriers of diffusion in surrounding white matter tissue $[47,48]$. The quantitative sensitivity to brain pathology is a major advantage of DTI over standard T1 and T2 weighted MRI scans.

The purpose of the present study was to use DTI and structural MRI to examine brain integrity (as measured by FA and MD) and volume in the basal ganglia and hippocampus among older HIVinfected adults with histories of stimulant abuse. Overall, we expected that past stimulant users would evidence greater basal ganglia and hippocampal compromise than drug naïve participants. These decrements would be represented by lower FA values and higher MD values among patients who reported histories of substance abuse/ dependence, thus demonstrating a breakdown of structural barriers of diffusion. Based upon findings reported by [38] we hypothesized that length of abstinence would be associated with imaging metrics (i.e., FA, $\mathrm{MD}$, volume), such that individuals with shorter abstinence periods would demonstrate more basal ganglia and hippocampal compromise than those with longer abstinent periods. We also expected to observe larger basal ganglia volume (functional compensation) and decreases in hippocampal volume among individuals who reported past abuse.

\section{Method}

UCLA and VA Institutional Review Board (IRB) approval was obtained prior to implementing study procedures. Written informed consent was obtained from all participants in the study.

\section{Participants}

Participants included 20 older (age 50+) HIV + adults (age $\mathrm{M}=53.25$, $\mathrm{SD}=4.2$ years; education $\mathrm{M}=13.5, \mathrm{SD}=2.0$ years) recruited from local infectious disease clinics and community agencies as part of a larger study examining the effects of aging and HIV on neuropsychological 
Citation: Thames AD, Foley JM, Panos SE, Singer EJ, Patel SM, El-Saden S and Hinkin CH et al. (2011) Past Stimulant Abuse is Associated with Reduced Basal Ganglia and Hippocampal Integrity in Older HIV+ Adults: A Diffusion Tensor Imaging Study. J AIDS Clinic Res 2:129. doi:10.4172/21556113.1000129

Page 3 of 6

outcomes. (See Table 1 for sample demographics). Prior to study entry, participants received explanation of study procedures and completed consent forms.

Inclusion criteria: (1) 18 years of age or older; (2) HIV seropositive - Status confirmed based upon serologic testing for HIV antibody [screening ELISA, confirmed by Western blot if positive]; (3) willing and able to comply with study procedures; (4) willing and able to provide written informed consent; (5) demonstrated at least 6th grade English reading level.

Exclusionary criteria: (1) Unable to provide informed consent; (2) presented with a non-HIV neurologic disorder, such as moderate-severe head injury, seizure disorder, demyelinating illness, or CNS neoplasm; (3) have history of an HIV-associated CNS opportunistic infection (e.g. toxoplasmosis) or neoplasm; (4) presented with a current psychotic spectrum disorder or mood disorder; (5) presented with substance abuse/dependence within the past year; (6) presented with past abuse of hallucinogens, opiates, or alcohol (7) if MRI was contraindicated (e.g. due to claustrophobia or metallic inclusions); (8) recent drug use (verified by urine toxicology screens).

\section{Past stimulant use}

Past stimulant abuse and dependence (greater than 12 months) was gathered based upon self-report from the Structured Clinical Interview for DSM-IV disorders [49]. A majority of our sample who met DSMIV criteria for abuse also met criteria for dependence; therefore we combined these individuals into one group. Based upon SCID data, we classified participants into stimulant $(\mathrm{n}=12)$ and stimulant- free $(\mathrm{n}=$

\begin{tabular}{|c|c|c|c|}
\hline \multirow[b]{2}{*}{ Age in years } & \multirow{2}{*}{$\begin{array}{c}\begin{array}{c}\text { Stimulant free }(\mathrm{n} \\
=8)\end{array} \\
53.2(7.0)\end{array}$} & \multicolumn{2}{|c|}{$\begin{array}{l}\text { Stimulant abuse/dependence }(n=12) \\
\text { p value }\end{array}$} \\
\hline & & $54.5(3.6)$ & $p>.05$ \\
\hline Years of education & $14.0(2.2)$ & $13.7(1.8)$ & $p>.05$ \\
\hline$\%$ Male & 75 & 83 & $p>.05$ \\
\hline Ethnicity & & & $p<.05$ \\
\hline $\begin{array}{c}\% \text { African Ameri- } \\
\text { can }\end{array}$ & 75.0 & 58.3 & \\
\hline \% Caucasian & 8.3 & 33.3 & \\
\hline \% Hispanic & 8.3 & 8.3 & \\
\hline$\%$ Asian & 0 & 0 & \\
\hline$\%$ Other & 8.3 & 0 & \\
\hline $\begin{array}{l}\text { Median Recent } \\
\text { CD4 count }\end{array}$ & $\begin{array}{c}416.5 \\
\text { (I.Q. range }-186)\end{array}$ & $\begin{array}{c}468.0 \\
(\mathrm{IQ} \text { range }-504)\end{array}$ & $p>.05$ \\
\hline Nadir CD4 count & $\begin{array}{c}97 \\
\text { (I.Q. range }-258)\end{array}$ & $\begin{array}{c}200 \\
(\mathrm{IQ} \text { range }-639)\end{array}$ & $p<.05$ \\
\hline $\begin{array}{c}\% \text { undetectable } \\
\text { viral load }\end{array}$ & 62 & 50 & $p>.05$ \\
\hline$\%$ AIDS diagnosisa & 66 & 50 & $p>.05$ \\
\hline $\begin{array}{l}\text { Length of ARV } \\
\text { therapy }\end{array}$ & 8 & 8 & $p>.05$ \\
\hline 0-11 months & 0 & 0 & \\
\hline $1-3$ years & 13 & 17 & \\
\hline$\%$ over 3 years & 87 & 83 & \\
\hline $\begin{array}{l}\text { Length of HIV } \\
\text { infection (years) }\end{array}$ & $16(1.2)$ & $17(2.4)$ & $p>.05$ \\
\hline
\end{tabular}

a. Based upon CD4< 200 or Opportunistic infection

Table 1 : Sample Characteristics $(\mathrm{N}=20)$.

\begin{tabular}{|l|c|c|c|}
\hline \multicolumn{1}{|c|}{ Data $(\mathrm{N}=20)$} & Stimulant free $(\mathrm{n}=8)$ & $\begin{array}{c}\text { Stimulant abuse/ } \\
\text { dependence }(\mathrm{n}=12)\end{array}$ & $\mathrm{p}$ value \\
\hline Basal Ganglia FA & $0.24(.0002)$ & $0.17(.0006)$ & $\mathrm{p}<.05^{*}$ \\
\hline Basal Ganglia MD & $0.34(.0004)$ & $0.42(.0007)$ & $\mathrm{p}<.05^{*}$ \\
\hline $\begin{array}{l}\text { Basal Ganglia } \\
\text { Volume }\end{array}$ & $6.7 \mathrm{~mm} 3\left(.08 \mathrm{~mm}^{3}\right)$ & $6.2 \mathrm{~mm} 3\left(1.1 \mathrm{~mm}^{3}\right)$ & $\mathrm{p}>.05$ \\
\hline Hippocampal FA & $.08(.02)$ & $0.10(.04)$ & $\mathrm{p}>.05$ \\
\hline Hippocampal MD & $0.10(.00006)$ & $0.12(.00010)$ & $\mathrm{p}<.05^{*}$ \\
\hline $\begin{array}{l}\text { Hippocampal } \\
\text { Volume }\end{array}$ & $4.6 \mathrm{~mm} 3\left(.05 \mathrm{~mm}^{3}\right)$ & $3.8 \mathrm{~mm}^{3}\left(1.1 \mathrm{~mm}^{3}\right)$ & $\mathrm{p}>.05$ \\
\hline
\end{tabular}

* Statistically significant at $p<.05$

Table 2: Basal Ganglia and Hippocampus Fractional Anisotropy (FA), Mean Diffusivity (MD), and Volumetric.

8) groups (see table 1 for demographics). With respect to other drugs, most of our sample $(n=18)$ reported past alcohol $(n=18)$ and marijuana $(\mathrm{n}=3)$ use, with $2 / 18$ reporting abuse ( $>12$ months). Statistical analyses were conducted with and without these two participants. Eliminating these participants did not change study results; therefore, we elected to include the two participants in the final analyses.

\section{DTI acquisition}

MRI images were obtained using a 1.5T Magnetom Sonata scanner (Siemens AG, Erlangen, Germany), using a single-shot, echo-planar acquisition sequence $(\mathrm{TR} / \mathrm{TE}=10,000 / 88 \mathrm{~ms}$; four $\mathrm{b}=0 / \mathrm{b}=750 \mathrm{~s} / \mathrm{mm} 2$ 4 averages; matrix $=128 \times 128,256 \times 256 \mathrm{~mm}$ field of view; slice thickness $=2 \mathrm{~mm}$ ). The protocol included an initial multiplanar scout, axial-oblique, proton density-/T2-weighted double spin-echo, and sagittal whole-brain high-resolution T1-weighted MRI sequences. Scans planes were oriented perpendicular to the AC-PC line.

\section{ROI Delineation}

Subcortical ROIs (caudate, putamen, hippocampus) were extracted from the T1 image for each subject using LONI Brain Parser. The LONI Brain Parser software is an automated learning-based algorithm that efficiently performs whole brain image segmentation to parse an input MRI image into 56 anatomical structures of interest [50].

\section{DWI-T1 Registration}

Raw diffusion-weighted images were co-registered to each subjects T1 weighted image using a two-stage process. First, eddy current and motion correction was performed by affine (12-parameter) registration of each DWI to the corresponding b0 volume using FMRIB's Linear Image Registration Tool (FLIRT). Next, a second affine transformation was computed, again with FLIRT, to map the b0 volume into the T1 space. These two transformations were multiplied and then applied to each DWI in a single step to minimize interpolation artifacts. Accurate registration to MNI-152 space was visually verified, and the b-matrix corresponding to the DWI acquisitions was corrected in accord with these transformations.

\section{DTI Reconstruction and Analysis}

We then used the Diffusion Imaging Reconstruction and Analysis Collection (DIRAC) modules, available on the Pipeline tool from the Laboratory of NeuroImaging (LONI) to perform the diffusion tensor reconstruction and anisotropy index calculations. First, the secondorder diffusion tensors were calculated at each voxel using a weighted linear least-squares approach. The tensors were diagonalized to yield the three principal diffusion directions (eigenvectors) and corresponding diffusivities (eigenvalues). Anisotropy statistics were then calculated 
Citation: Thames AD, Foley JM, Panos SE, Singer EJ, Patel SM, El-Saden S and Hinkin CH et al. (2011) Past Stimulant Abuse is Associated with Reduced Basal Ganglia and Hippocampal Integrity in Older HIV+ Adults: A Diffusion Tensor Imaging Study. J AIDS Clinic Res 2:129. doi:10.4172/21556113.1000129

Page 4 of 6

from these eigenvalues for each subject in the T1 space. These indices were averaged over each subcortical ROI using the FMRIB's fslstats utility.

\section{Volumetric analysis}

Basal ganglia and hippocampal volume data were extracted from the T1 weighted scans using the UCLA Laboratory of Neuroimaging LONI) BrainParser.

\section{Results}

\section{Demographics and HIV-disease variables}

Former stimulant abusers did not significantly differ from nonstimulant abusers on age, education, gender, or recent CD4 count. However, stimulant-naïve individuals reported significantly lower nadir CD4 counts than former stimulant abusers (see table 1).

The first analyses compared FA and MD measures of the basal ganglia and hippocampus as a function of past stimulant abuse. Participants who reported past stimulant abuse demonstrated lower FA values in the basal ganglia when compared to participants who did not report past abuse, $\mathrm{t}(18)=2.302, \mathrm{p}=.03$. Past stimulant abusers demonstrated greater diffusivity $(\mathrm{MD})$ in the basal ganglia $t(18)=-2.120, \mathrm{p}=.03$ and hippocampus $\mathrm{t}(18)=-3.124, \mathrm{p}=.006$ than stimulant-naïve individuals. Among the stimulant drug group, length of abstinence was significantly correlated with MD of the caudate, $r(11)=-.78, p=.04$.

\section{Volume findings}

There were no significant group differences between past stimulant users and non-users in basal ganglia volume $\mathrm{t}(18)=-.459, \mathrm{p}=.654$. However, there was a statistical trend towards decreased hippocampal volume among past stimulant users relative to non-users, $\mathrm{t}(18)=1.562$, $\mathrm{p}=.10$.

\section{Discussion}

To our knowledge, this is the first application of DTI to compare basal ganglia and hippocampal integrity in older HIV+ adults with and without histories of stimulant abuse. We observed lower fractional anisotropy (FA) values in our participants with histories of substance abuse, suggesting that older adults with histories of stimulant abuse may be at disproportionate risk for breakdown in microstructural barriers. In addition, length of abstinence was associated higher diffusivity in the caudate, which is consistent with prior knowledge that the caudate is a region that is highly susceptible to the effects of HIV and stimulant [51]. Our findings are consistent with prior studies demonstrating reduced microstructural integrity in the basal ganglia and subcortical white matter of patients with HIV encephalitis [52,53], stimulant abuse histories [33], and basal ganglia anisotropy in HIV [54]. Although gray matter is generally isotropic in nature when compared to white matter, the differences in the measured anisotropy in gray matter may reflect factors such as injury or morphologic variation in highly aligned cellular structures (e.g., axons) or replacement of axonal fibers with less ordered cells (e.g., glial cells) [55].

Basal ganglia dysfunction is one of the hallmarks of HIV infection and healthy older adults are also particularly vulnerable to these changes. Numerous investigations have demonstrated relationships between $\mathrm{HIV}$-associated neurological dysfunction within the basal ganglia and impairments in cognitive functions of attention/working memory, information processing speed, motor functions, and executive functions [56] in addition to declines in instrumental activities of daily living [IADLs] [57,58].
Normal aging confers its own risk for neuropathological processes and HIV+ older adults are likely to be more vulnerable to these changes given the additive, if not synergistic, effects of these processes upon neurocognitive and neurophysiogical function. It has been demonstrated that markers of striatal dopamine function decline with age and measures of nigrostriatal neurons have indicated a loss of 70\% in the putamen after the age of 55 [59]. In addition, the age-related loss of dopamine appears to accelerate after age $60[59,60]$.

We observed differences in diffusivity and a trend in hippocampal decline among past stimulant users, which is consistent with prior studies examining stimulant use and hippocampal dysfunction [36] and with expected age-associated changes. Longitudinal studies of hippocampal volume decreases have ranged from $0.8 \%-2.0 \%[61,62]$. Lack of statistical significance in the current study may be a function of limited power.

Due to our modest sample size, we limited our focus to stimulant use as opposed to alcohol abuse or opiate use, which are drugs that have also been demonstrated to be associated with neurological compromise and which target alternative receptor systems and confer vastly divergent neurochemical and physiological effects. Furthermore, we were unable to separate out effects from METH versus cocaine given the limited subsample of METH users $(n=4)$ and given the presence of combined substance use among a limited range of participants $(n=3)$. However, rather than exclude our METH using individuals, we combined our METH and cocaine groups given the overlapping biochemical properties of these substances of abuse. Given the preliminary nature of the study, we were unable to gather estimates of severity, which would have been optimal. Although there were no statistically significant differences in reported length of ARV therapy and current medication adherence, we were unable to gather data regarding overall medication adherence since first starting ARV therapy. It is possible that our former drug abuse participants would be more likely demonstrate a fluctuating pattern of medication adherence, which could also influence neurological integrity.

Unlike prior studies [33], we were unable to document volumetric differences between stimulant abuse groups in basal ganglia structures. Perhaps our inability to observe volumetric differences is attributable to lack of an appropriate control group. Future investigations should include an HIV- seronegative older adult group.

Despite the aforementioned limitations, we believe our findings are important for a number of reasons. First, our results suggest that older HIV+ adults with histories of stimulant abuse are vulnerable to basal ganglia and hippocampal dysfunction. Despite our rather limited sample size, the effect sizes of the current study are encouraging and warrant for future investigations into the deleterious effects of past substance use for older adults with HIV using a larger sample of HIV+ and HIV- seronegative individuals. It has been well-established that current drug abuse/dependence is associated with neurocognitive abnormalities. However, the neurocognitive effects of past drug use are less clear with some studies demonstrating no differences after even prolonged abstinence to $[63,64]$ to those finding robust differences $[25,65]$. There are a number of reasons that may explain why neuropsychological findings may differ; many studies examining neuropsychological performance fail to account for premorbid factors such as cognitive reserve capacity [66] that can result in performance variation. Furthermore, discrepancies may be secondary, at least in part, to insufficiently sensitive and precise cognitive measurement, to inclusion of participants with comorbid disorders (e.g., Hepatitis C), to measures of HIV disease severity, and to inadequate control in 
Citation: Thames AD, Foley JM, Panos SE, Singer EJ, Patel SM, El-Saden S and Hinkin CH et al. (2011) Past Stimulant Abuse is Associated with Reduced Basal Ganglia and Hippocampal Integrity in Older HIV+ Adults: A Diffusion Tensor Imaging Study. J AIDS Clinic Res 2:129. doi:10.4172/21556113.1000129

Page 5 of 6

measuring time to last use of drug. Future research should consider further identifying the distinct changes associated with the combined impacts of HIV, advanced age, and stimulant abuse history. Appropriate methodological goals should entail inclusion of a larger sample in the service of enhancing statistical power, additional sample cells reflected by the presence versus absence of current stimulant use, older age, and HIV-seropositive status in order to further refine and provide support for the current findings documented here, as well as a refined appreciation of severity of HIV. Addressing these issues will serve to increase our understanding of the additive versus synergistic effects of the combined impacts of HIV status, age and stimulant abuse upon neuropathological outcome.

The present findings have important scientific and clinical implications for the field of NeuroAIDS, aging, and substance abuse. As mentioned previously, both cocaine and METH has been found to deplete dopaminergic neurons in the basal ganglia, which may predispose individuals to Parkinsonism [67]. Hence, coupled with age associated changes and HIV-associated neurological dysfunction, the cognitive and clinical profile of these participants may appear much different than that of HIV+ adults who have successfully aged.

\section{References}

1. Becker JT, Lopez OL, Dew MA, Aizenstein HJ (2004) Prevalence of cognitive disorders differs as a function of age in HIV virus infection. AIDS 18: S11-S18.

2. Cherner M, Ellis RJ, Lazzaretto D, Young C, Mindt MR, et al. (2004) Effects of HIV-1 infection and aging on neurobehavioral functioning: Preliminary findings. AIDS 18: S27-S34.

3. Hardy DJ, Hinkin CH, Satz P, Stenquist P, van Gorp W, et al. (1999) Age differences and neurocognitive performance in HIV-infected adults. NZ J Psychol 28: 94-101.

4. Hinkin CH, Castellon SA, Atkinson JH, Goodkin K (2001) Neuropsychiatric aspects of HIV infection among older adults. J Clin Epidemiol 54: S44-S52.

5. Sacktor N, Skolasky R, Selnes OA, Watters M, Poff P, et al. (2007) Neuropsychological test profile differences between young and old human immunodeficiency virus-positive individuals. J Neurovirol 13: 203-209.

6. Stoff DM, Khalsa JH, Monjan A, Portegies P (2004) Introduction: HIVIAIDS and aging. AIDS 18: S1-S2

7. van Gorp WG, Miller EN, Marcotte TD, Dixon W, Paz D, Selnes O, et al. (1994) The relationship between age and cognitive impairment in HIV-1 infection: Findings from the Multicenter AIDS Cohort Study and clinical cohort. Neurology 44: 929-935

8. Hinkin $\mathrm{CH}$, Hardy DJ, Mason KI, Castellon SA, Durvasula RS, Lam MN, et al. (2004) Medication adherence in HIV-infected adults: Effect of patient age cognitive status, and substance abuse. AIDS 18: S19-S25.

9. Martin EM, Pitrak DL, Weddington W, Rains NA, Nunnally G, Nixon H, et al. (2004) Cognitive impulsivity and HIV serostatus in substance dependent males. J Int Neuropsychol Soc 10: 931-938.

10. Nath A, Maragos WF, Avison MJ, Schmitt FA, Berger JR (2001) Acceleration of HIV dementia with methamphetamine and cocaine. J Neurovirol 7: 66-71.

11. Nath A, Hauser KF, Wojna V, Booze R M, Maragos W et al. (2002) Molecular basis for interactions of HIV and drugs of abuse. J Acquir Immune Defic Syndr 31: S62-S69.

12. Goodkin K, Shapshak P, Metsch LR, McCoy CB, Crandall KA, et al. (1998) Cocaine abuse and HIV-1 Infection: epidemiology and neuropathogenesis. J Neuroimmunol 83: 88-101.

13. Durvasula RS, Myers HF, Satz P, Miller EN, Morgenstern H, et al. (2000) HIV1 , cocaine and neuropsychological performance in African American men. J Int Neuropsychol 6: 322-335.

14. Gfroerer J, Penne M, Pemberton M, Folsom R(2003) Substance abuse treatment needs among older adults in 2020: The impact of the aging babyboom cohort. Drug Alcohol Depend 69: 127-135.

15. Baldwin GC, Tashkin DP, Buckley DM, Park AN, Dubinett SM, et al. (1997)
Marijuana and cocaine impair alveolar macrophage function and cytokine production. Am J Respir Crit Care Med 156: 1606-1613.

16. Einstein TK, Hilburger ME (1998) Opioid modulation of immune responses: effects on phagocyte and lymphoid cell populations. J Neuroimmunol 83: 3644

17. Stanulis ED, Jordan SD, Rosecrans JA, Holsapple MP (1997) Disruption of Th1/Th2 cytokine balance by cocaine is mediated by corticosterone. Immunopharmacology 37: 25-33.

18. Gardner B, Zhu LX, Roth MD, Tashkin DP, Dubinett SM, et al. (2004) Cocaine modulates cytokine and enhances tumor growth through sigma receptors. J Neuroimmunol 147: 95-98.

19. Dhillon N, Williams R, Peng F, Tsai Y, Dhillon S, et al. (2007) Cocaine-mediated enhancement of virus replication in macrophages: Implications for human immunodeficiency virus-associated dementia. J Neurovirol 13: 483-495.

20. Peterson PK, Gekker G, Chao CC, Schut R, Molitor TW, et al. (1991) Cocaine potentiates HIV-1 replication in human peripheral blood mononuclear cell cocultures involvement of transforming growth factor-beta. J Immunol 146: 81 84.

21. Volkow ND, Fowler JS, Wang GJ, Hitzemann R, Logan J, et al. (1993) Decreased dopamine D2 receptor availability is associated with reduced frontal metabolism in cocaine abusers. Synapse 14: 169-177.

22. Dhillon NK, Peng F, Bokhari S, Callen S, Shin SH, et al. (2008) Cocainemediated alteration in tight junction protein expression and modulation of CCL2/CCR2 axis across the blood-brain barrier: implications for HIV-dementia J Neuroimmune Pharmacol 3: 52-56.

23. Toberek M, Lee YW, Pu H, Malecki A, Flora G, et al. (2003) HIV-Tat protein induces oxidative and inflammatory pathways in brain endothelium. J Neurochem 84: 169-179

24. Ersche KD, Barnes A, Jones PS, Morein-Zamir S, Robbins TW, et al. (2011) Abnormal structure of frontostriatal brain systems is associated with aspects of I mpulsivity and compulsivity in cocaine dependence. Brain 134: 2013-2024.

25. Meade CS, Lowen SB, MacLean RR, Key MD, Lukas SE (2011) fMRI brain activation during a delay discounting task in HIV-positive adults with and without cocaine dependence. Psychiatry Res 192: 167-175.

26. Substance Abuse and Mental Health Services Administration - Office of Applied Statistics (2006). National Survey on Drug Use and Health, issue 37.

27. Barr AM, Panenka WJ, MacEwan GW, Thornton AE, Lang DJ, et al. (2006) The need for speed: an update on methamphetamine addiction. J Psychiatry Neurosci 31: 301-313.

28. Volkow ND, Chang L, Wang G, Fowler JS, Leonido-Yee M, et al. (2001) Association of dopamine transporter reduction with psychomotor impairment in methamphetamine abusers. Am J Psychiatry 158: 377-382.

29. Harvey DC, Lacan G, Tanious SP, Melega WP (2000) Recovery from methamphetamine induced long-term nigrostriatal dopaminergic deficits without substantia nigra cell loss. Brain Res 871: 259-270.

30. Miller DB, O'Callaghan JP (2003) Elevated environmental temperature and methamphetamine neurotoxicity. Environ Res 92: 48-53.

31. Moszczynska A, Fitzmaurice P, Ang L, Kalasinsky, Schmunk K, et al. (2004) Why is parkinsonism not a feature of human methamphetamine users? Brain 127: $363-370$

32. Jernigan TL, Gamst AC, Archibald, SL, Fennema-Notestine, Rivera-Mindt M et al. (2005) Effects of methamphetamine dependence and HIV infection on cerebral morphology. Am J Psychiatry 162: 1461-1472.

33. Chang L, Cloak C, Patterson K, Gron C, Miller EN, et al. (2005) Enlarged striatum in abstinent methamphetamine abusers: a possible compensatory response. Biol Psychiatry 57: 967-974.

34. Chang L, Alicata D, Ernst T, Volkow N (2007) Structural and metabolic brain changes in the striatum associated with methamphetamine abuse. Addiction 102: 16-32.

35. Chung A, Lyoo IK, Kim SJ, Hwang J, Bae SC, et al. (2007) Decreased frontal white-matter integrity in abstinent methamphetamine abusers. Int $J$ Neuropsychopharmacology10: 765-775.

36. Thompson PM, Hayashi KM, Simon SL, Geaga J.A, Hong MS (2004) Structura 
Citation: Thames AD, Foley JM, Panos SE, Singer EJ, Patel SM, El-Saden S and Hinkin CH et al. (2011) Past Stimulant Abuse is Associated with Reduced Basal Ganglia and Hippocampal Integrity in Older HIV+ Adults: A Diffusion Tensor Imaging Study. J AIDS Clinic Res 2:129. doi:10.4172/21556113.1000129

abnormal ities in the brains of human subjects who use methamphetamine. $\mathrm{J}$ Neurosci 24: 6028-6036.

37. Venkatesan A, Uzasci L, Chen Z, Rajbhandari L, Anderson C, et al. (2011) Impairment of adult hippocampal neural progenitor proliferation by methamphetamine: Role for nitrotyrosination. Molecular Brain 4: 1-14.

38. Kim SJ, Lyoo IK, Hwang J, Sung YH, Lee HY, et al. (2005) Frontal glucose hypometabolism in abstinent methamphetamine users. Neuropsychopharmacology 30: 1383-1391.

39. Bell JE (2004) An update on the neuropathology of HIV in the HAART era. Histopathology 45: 549-559.

40. Cherner M, Masliah E, Ellis RJ, Marcotte TD, Moore DJ, et al. (2002) Neurocognitive dysfunction predicts postmortem findings of HIV encephalitis. Neurology 59: 1563-1567.

41. Trillo-Pazos G, Diamanturos A, Rislove L, Menza T, Chao W, et al. (2003) Detection of HIV-1 DNA in microglia/macrophages, astrocytes and neurons isolated from brain tissue with HIV-1 encephalitis by laser capture microdissection. Brain Pathol 13: 144-154.

42. Aylward EH, Henderer JD, McArthur JC, Brettschneider PD, Harris GJ, et al (1993) Reduced basal ganglia volume in HIV-1-associated dementia: results from quantitative neuroimaging. Neurology 43: 2099-2104.

43. Jernigan TL, Archibald S, Hesselink JR, Atkinson JH, Velin RA, et al. (1993) Magnetic resonance imaging morphometric analysis of cerebral volume loss in human immunodeficiency virus infection. Arch Neurol 50: 250-255.

44. Huang H, Zhang J, Wakana S, Zhang W, Ren T, et al. (2006) White and gray matter development in human fetal, newborn and pediatric brains. Neuroimage 33: $27-38$

45. Liu T, Li H, Wong K, Tarokh A, Guo L, et al. (2007) Brain tissue segmentationbased on DTI data. Neuroimage 38: 114-123.

46. Charlton RA, Barrick TR, Mclntyre DJ, Shen Y, O'Sullivan M, et al. (2006) White matter damage on diffusion tensor imaging correlates with age-related cognitive decline. Neurology 66: 217-222.

47. Gass A, Niendorf T, Hirsch JG (2001) Acute and chronic changes of the apparent diffusion coefficient in neurological disorders - biophysical mechanisms and possible underlying histopathology, J Neurol Sci, 186 Suppl 1: S15-S23.

48. Horsfield MA, Jones DK (2002) Applications of diffusion-weighted and diffusion tensor MRI to white matter diseases - a review. NMR Biomed 15: 570-577.

49. Spitzer RL, Williams JB, Gibbon M, First MB (1992) The Structured Clinical Interview for DSM-III-R (SCID). I: History, rationale, and description. Arch Gen Psychiatry 49: 624-629.

50. Tu Z, Narr KL, Dollar P, Dinov I, Thompson PM, et al. (2008) Brain anatomica structure segmentation by hybrid discriminative/generative models. IEEE Trans Med Imaging 27: 495-508.

51. Taylor MJ, Alhasson OM, Schweinsburg, BC, Videen JS, Grant I (2000) MR spectroscopy in HIV and stimulant dependence HNRC Group. HIV Neurobehavioral Research Center. J Int Neuropsychol Soc, 83-85.

52. Raja F, Sherriff FE, Morris CS, Bridges LR, Esiri MM (1997) Cerebral white matter damage in HIV infection demonstrated using beta-amyloid precursor protein immunoreactivity. Acta Neuropathol 93:184-189.

53. Carasig D, Chang L, Arnold S, Tomasi D, Cloak C, et al. (2003) Voxel-based morphometric study of HIV-1 patients at 4 tesla. [Abstract]. International Society of Magnetic Resonance in Medicine; July; Toronto, Canada p. 2638

54. Ragin AB, Wu Y, Storey P, Cohen BA, Edelman RR, et al. (2005) Diffusion tensor imaging of subcortical brain injury in patients infected with human immunodeficiency virus. J Neurovirol 11: 292-298.

55. Nebuloni M, Pellegrinelli A, Ferri A, Bonetto S, Boldorini R, et al. (2001) Beta amyloid precursor protein and patterns of HIV p24 immunohistochemistry in different brain areas of AIDS patients. AIDS 15: 571-575.

56. Heaton RK, Grant I, Butters N, White DA, Kirson D, et al. (1995) The HNRC 500-neuropsychology of HIV infection at different disease stages. HIV Neurobehavioral Research Center. J Int Neuropsychol Soc 1: 231-251.

57. Heaton RK, Marcotte TD, Mindt MR, Sadek, J, Moore DJ, et al. (2004) The impact of HIV-associated neuropsychological impairment on everyday functioning. J Int Neuropsychol Soc 10: 317-331.
58. Thames AD, Kim MS, Becker BW, Foley JM, Hines LJ, et al. (2010) Medication and finance management among HIV-infected adults: The impact of age and cognition. J Clin Exp Neuropsychol 33: 200-209.

59. Carlsson A, Winblad B (1976) Influence of age and time interval between death and autopsy on dopamine and 3-methoxytyramine levels in human basal ganglia. J Neural Transm 38: 271-276.

60. Carlsson A, Nyberg P, Winbald B (1984) The influence of age and other factors on concentrations of monoamines in the human brain. In: Nyberg P, editor. Brain Monoamines in Normal Aging and Dementia. Sweden: Umea Medica Dissertations; $53-84$

61. Fjell AM, Walhovd KB, Fennema-Notestine C, McEvoy, LK, Haglar DJ, et al (2009) One-year brain atrophy evident in healthy aging. J Neurosci 29: 15223 15231.

62. Raz N (2004) The aging brain observed in vivo: differential changes and thei modifiers. In: Cabeza R, Nyberg L, Park DC, editors. Cognitive Neuroscience of Aging: Linking Cognitive and Cerebral Aging. New York: Oxford University Press; $17-55$.

63. Chang L, Ernst T, Speck O, Patel H, DeSilva M, et al. (2002) Perfusion MR and computerized cognitive test abnormalities in abstinent methamphetamine users. Psychiatry Res 114: 65-67.

64. Cherner M, Bousman C, Everall I, Barron D, Letendre S, et al. (2010) Cytochrome P450-2D6 extensive metabolizers are more vulnerable to methamphetamineassociated neurocognitive impairment: Preliminary findings. JINS 16: 890-901.

65. Bolla KI, Rothman R, Cadet JL (1999) Dose-related neurobehavioral effects of chronic cocaine use. J Neuropsychiatry Clin Neurosci 11: 361-369.

66. Satz P, Morgenstern H, Miller EN, Selnes OA, McArthur JC, et al. (1993) Low education as a possible risk factor for cognitive abnormalities in HIV-1: Findings from the multicenter AIDS Cohort Study (MACS). J Acquir Immune Defic Synd 6: 503-511.

67. Koutsilieri E, Sopper S, Scheller C, Meulen V, Riederer P (2002) Parkinsonism in HIV dementia. J Neural Transm 109: 767-775.

68. Carlsson A, Nyberg P, Winbald B (1984) The influence of age and other factors on concentrations of monoamines in the human brain. In: Nyberg $\mathrm{P}$, editor Brain Monoamines in Normal Aging and Dementia. Sweden: Umea Medical Dissertations; $53-84$

69. Center for Disease Control (2007) HIVIAIDS Surveillance Report, 2005 (Vol. 17, Rev ed., pp.1-54). Atlanta, GA: U.S. Department of Health and Human Services.

70. Hult B, Chana G, Masliah E, Everall I (2008) Neurobiology of HIV. International Review of Psychiatry, 20: 3-13. 